\title{
Effects of chronic hepatitis $B$ infection and viremia on the reproductive potential of Egyptian males
}

\author{
Original \\ Kamal Abd El-Hafez ${ }^{1}$, Ehab Fawzy', Emad Eldien Kamal', Sahar Hassany', Mohammed \\ Article \\ Zakaraia $^{3}$, Rofaida R. Shehata ${ }^{1}$
}

${ }^{1}$ Departments of Dermatology, Venereology and Andrology, ${ }^{2}$ Gastroenterology and

Tropical Medicine, ${ }^{3}$ Clinical Pathology, Faculty of Medicine, Assiut University, Assiut, Egypt

\section{ABSTRACT}

Purpose: To evaluate the effect of chronic hepatitis B infection on semen parameters and reproductive hormones in Egyptians. Patients and methods: In this study, 104 males were included. They were classified into two groups: 73 patients with chronic hepatitis B without liver cirrhosis (group 1) and 31 healthy volunteers (group 2). Semen samples were analyzed using a computer-aided semen analyzer. Serum levels of follicle-stimulating hormone, luteinizing hormone, total testosterone, free testosterone, estradiol, prolactin, and sex hormone-binding globulin were measured by enzyme-linked immunosorbent assay. PCR was also evaluated. Liver condition was evaluated by liver function tests and abdominal sonography.

Results: Semen parameters were affected in patients. There was a significant negative correlation between semen parameters (sperm count, motility, and morphology) and level of viremia. Moreover, a significant negative correlation was detected between level of viremia and serum levels of free testosterone and follicle-stimulating hormone. However, a positive correlation was noted between level of viremia and serum levels of prolactin and estradiol.

Conclusion: Hepatitis B virus may have profound implications on male fertility potential.

Key Words: Hepatitis B, hormones, PCR, semen

Received: 18 December 2018, Accepted: 28 February 2019

Corresponding Author: Rofaida R. Shehata, MSc, Department of Dermatology and Venereology and Andrology, Faculty of Medicine, Assiut University, Assiut 71526, Egypt, Tel.: +2 01006897580, E-mail: rofaida.refaat@yahoo.mail

ISSN: 2090-6048, December 2018, Vol.8, No.4

\section{INTRODUCTION}

The implications of hepatitis B virus (HBV) infection on male fertility potential are still far from clear ${ }^{[1]}$. HBV is able to integrate into sperm chromosomes ${ }^{[2]}$ causing chromosomal instability and metaphase chromosome stickiness $^{[3]}$. Thus, HBV infection can induce hereditary defects in male germ cells and impair spermatogenesis. In addition, several studies have reported negative effects of $\mathrm{HBV}$ on reproductive hormonal balance ${ }^{[4]}$.

Therefore, much interest has been focused on the relationship between $\mathrm{HBV}$ infection and male reproduction ${ }^{[5]}$.

\section{AIM OF THE WORK}

The aim is to evaluate and correlate the effect of chronic HBV infection on semen parameters and levels of reproductive hormones in Egyptian males.

\section{PATIENTS AND METHODS}

The study was conducted in Assiut University Hospitals, Assiut, Egypt between August 2014 and August 2015.

The study was approved by the Institutional Ethics and Research Committee of Faculty of Medicine, Assiut University. Informed consent was obtained from all study patients.
This study included 73 male patients with chronic HBV infection without liver cirrhosis (group 1) and 31 age-matched healthy volunteers (group 2). Patients were recruited from the Andrology and Gastroenterology outpatient clinics, Assiut University Hospitals, Assiut, Egypt.

Semen analysis was done using a computer-aided semen analyzer (Mira-9000 CASA Quick Use) (Mira Lab Egypt \& Middle East head office, Mokattam, Cairo, Egypt).

Serum levels of follicle-stimulating hormone (FSH), luteinizing hormone ( $\mathrm{LH})$, total testosterone (T. Tes), free testosterone (F. Tes), estradiol (E2), prolactin (PRL), and sex hormone-binding globulin were measured by enzymelinked immunosorbent assay.

Abdominal ultrasound was done for every patient for exclusion of liver cirrhosis. Liver function tests and hepatitis markers were done for all study patients.

Overall, 10 milliliters of venous blood samples was collected. Blood samples were centrifuged, and the sera were stored at $-55^{\circ} \mathrm{C}$ until further analysis.

T. Tes was measured using the testosterone enzyme immunoassay kit (catalog number: BC-1115) (BioCheck Inc., San Francisco, CA, USA). The normal range was $3-10 \mathrm{ng} / \mathrm{ml}$. F. Tes was measured using free 
testosterone kit (Diagnostics Biochem Canada Inc., London, Ontario, Canada) (catalog number: CAN-Fte-260). The normal range was $3.84-34.17 \mathrm{pg} / \mathrm{ml}$. LH was measured using LH enzyme immunoassay test kit (BioCheck Inc.) (catalog number: BC-1031). Its normal range was 1.24-7.8 $\mathrm{mIU} / \mathrm{ml}$. E2 was measured using estradiol enzyme immunoassay test kit (BioCheck Inc.) (catalog number: $\mathrm{BC}-1111)$. Its normal range was less than $60 \mathrm{pg} / \mathrm{ml}$. PRL was measured by using prolactin enzyme immunoassay test kit (BioCheck Inc.) (catalog number: BC-1037). Its normal range was 3-14.7 $\mathrm{ng} / \mathrm{ml}$. FSH was measured using FSH enzyme immunoassay test kit (BioCheck Inc.) (catalog number: BC-1029). Its normal range was up to $11 \mathrm{mIU} / \mathrm{ml}$. Sex hormone-binding globulin was measured using Microplate Enzyme Immunoassay test kit (Immunospec; Mayo Clinic, Arizona, FL, USA) (catalog number: E2-121). Its normal range was 10-57 nmol/1.

PCR was measured using artus HBV RG PCR kit (catalog number: 4506263, 4506265) (Qiagen $\mathrm{GmbH}$, Düsseldorf, Germany). The precision data of the artus HBV RG PCR kit allow determination of the total variance of the assay. The total variance consists of intra-assay variability, inter-assay variability, and inter-batch variability. Data obtained were used to determine the $\mathrm{SD}$, the variance, and the coefficient of variation for the specific pathogen and the internal control PCR.

\section{Exclusion criteria}

The following were the exclusion criteria:

1. Patients with genital infection, varicocele, hypogonadism or cryptorchidism, testicular atrophy, congenital bilateral absent vas, or obstructive infertility.

2. Any concomitant systemic illness.

\section{Inclusion criteria}

The following were the exclusion criteria:

1. Male patients with chronic HBV infection.

2. Healthy controls with normal semen parameters, negative serology for HBV, and normal liver functions.

\section{Statistical analysis}

Data entry analysis were done using SPSS, version 19 (Statistical Package for Social Science, Chicago, Illinois, USA). Data were presented as mean $\pm \mathrm{SD}$ and median/range. Mann-Whitney test was used to compare quantitative variables. Spearman correlation was done to measure correlations between quantitative variables. $\mathrm{P}$ value was considered statistically significant when less than 0.05 .

\section{RESULTS}

This study included 73 patients with chronic HBV without liver cirrhosis and 31 controls. The age of patients ranged from 18 to 46 years (mean, $32.23 \pm 7.25$ years). The age of controls ranged from 19 to 37 (mean, 29.39 \pm 5.24 ). The two groups were well matched for all demographic data

Sperm count, sperm motility, sperm morphology, and semen volume were more significantly declined in patients than in controls $(P=0.000)$ (Table 1).

We detected that $\mathrm{T}$. Tes was significantly lower in patients than in controls $(P=0.000)$. On the contrary, PRL and LH were significantly higher in patients $(P=0.000)$ (Table 2$)$.

Of the liver functions, albumin, total bilirubin, direct bilirubin, total protein, and alanine transaminase were significantly affected in patients (Table 3 ).

We detected a significant negative correlation between some semen parameters (sperm count, motility, and morphology) and the level of viremia in patients (Table 4)

Moreover, we found a significant negative correlation between level of viremia and serum levels of F. Tes and FSH in patients. On the contrary, a significant positive correlation between level of viremia and serum levels of PRL and E2 in patients was noted (Table 5).

Table 1: Semen parameters of patients and controls

\begin{tabular}{|c|c|c|c|}
\hline & Patients $(\mathrm{N}=73)$ & Control $(\mathrm{N}=31)$ & Pvalue \\
\hline \multicolumn{4}{|c|}{ Sperm count/million } \\
\hline Mean \pm SD & $30.10 \pm 26.26$ & $42.74 \pm 17.35$ & $0.000 *$ \\
\hline Median (range) & $23.5(1.2-113.9)$ & $37.0(22-94.2)$ & \\
\hline \multicolumn{4}{|l|}{ Sperm motility } \\
\hline Mean \pm SD & $32.59 \pm 18.00$ & $60.09 \pm 4.40$ & $0.000 *$ \\
\hline Median (range) & $30.8(0-74.4)$ & $61.0(51-68)$ & \\
\hline \multicolumn{4}{|l|}{ Semen volume } \\
\hline Mean \pm SD & $2.08 \pm 1.34$ & $3.89 \pm 1.26$ & $0.000 *$ \\
\hline Median (range) & $1.5(0.4-6)$ & $4.0(2-6)$ & \\
\hline \multicolumn{4}{|c|}{ Sperm morphology } \\
\hline Mean \pm SD & $20.14 \pm 11.03$ & $27.10 \pm 10.65$ & $0.005^{*}$ \\
\hline Median (range) & $20.0(0-57.58)$ & $23.0(16-62)$ & \\
\hline
\end{tabular}

* indicates statistical significant difference 
Table 2: Reproductive hormones of patients and controls

\begin{tabular}{llll}
\hline & Patients $(\mathrm{N}=73)$ & Control $(\mathrm{N}=31)$ & P value \\
\hline FSH & & & \\
Mean \pm SD & $5.17 \pm 4.90$ & $5.47 \pm 2.86$ & 0.386 \\
Median (range) & $5.3(0.01-25.5)$ & $5.0(1.5-10)$ & \\
Free testosterone & & & \\
Mean \pm SD & $26.37 \pm 31.39$ & $12.42 \pm 5.78$ & 0.394 \\
Median (range) & $12.1(0.01-122.9)$ & $10.0(4-26)$ & \\
Prolactin & & & $0.000^{*}$ \\
Mean \pm SD & $20.99 \pm 13.53$ & $6.39 \pm 2.60$ & \\
Median (range) & $16.7(5.1-75.9)$ & $6.0(3-13)$ & 0.062 \\
Estradiol & & & \\
Mean \pm SD & $12.57 \pm 13.78$ & $8.61 \pm 8.83$ & \\
Median (range) & $8.9(0.5-82.4)$ & $7.0(0.5-43)$ & \\
Total testosterone & & & $0.000 *$ \\
Mean \pm SD & $3.13 \pm 3.82$ & $5.90 \pm 2.23$ & \\
Median (range) & $1.5(0.1-13.5)$ & $6.0(3-9)$ & \\
LH & & & \\
Mean \pm SD & $11.58 \pm 4.97$ & $5.00 \pm 1.65$ & \\
Median (range) & $10.6(4.9-35.5)$ & $5.0(2-7)$ & \\
* indicates statistical significant difference & \\
FSH & & \\
\hline
\end{tabular}

FSH, follicle-stimulating hormone; LH, luteinizing hormone.

Table 3: Liver functions of patients and controls

\begin{tabular}{|c|c|c|c|}
\hline & Patients (N=73) & Control $(\mathrm{N}=31)$ & $P$ value \\
\hline \multicolumn{4}{|l|}{ ALP } \\
\hline Mean \pm SD & $218.25 \pm 79.53$ & $193.03 \pm 54.54$ & 0.101 \\
\hline Median (range) & $200(90-552.8)$ & $176(110-289)$ & \\
\hline \multicolumn{4}{|l|}{ Albumin } \\
\hline Mean \pm SD & $5.92 \pm 1.41$ & $4.42 \pm 0.49$ & $0.000^{*}$ \\
\hline Median (range) & $5.57(2.67-9.6)$ & $4.40(3.5-5.1)$ & \\
\hline \multicolumn{4}{|l|}{ GGT } \\
\hline Mean \pm SD & $34.00 \pm 26.42$ & $29.74 \pm 10.61$ & 0.966 \\
\hline Median (range) & $29.6(6.96-169.3)$ & $28.0(0-48)$ & \\
\hline \multicolumn{4}{|l|}{ Total bilirubin } \\
\hline Mean \pm SD & $1.35 \pm 0.45$ & $0.59 \pm 0.29$ & $0.000 *$ \\
\hline Median (range) & $1.36(0.54-2.54)$ & $0.60(0.2-1.1)$ & \\
\hline \multicolumn{4}{|l|}{ ALT } \\
\hline Mean \pm SD & $10.96 \pm 11.82$ & $22.77 \pm 9.07$ & $0.000^{*}$ \\
\hline Median (range) & $9.0(0-75.7)$ & $21.0(10-39)$ & \\
\hline \multicolumn{4}{|l|}{ Direct bilirubin } \\
\hline Mean \pm SD & $0.83 \pm 0.38$ & $0.17 \pm 0.10$ & $0.000^{*}$ \\
\hline Median (range) & $0.77(0.2-1.95)$ & $0.20(0-0.3)$ & \\
\hline \multicolumn{4}{|l|}{ Total protein } \\
\hline Mean \pm SD & $8.95 \pm 2.37$ & $7.47 \pm 0.65$ & $0.000 *$ \\
\hline Median (range) & $9.0(1.34-16.75)$ & $7.3(6.6-8.5)$ & \\
\hline \multicolumn{4}{|l|}{ AST } \\
\hline Mean \pm SD & $25.87 \pm 25.64$ & $20.42 \pm 7.91$ & 0.402 \\
\hline Median (range) & $21.8(0-190.7)$ & $21.0(6-36)$ & \\
\hline
\end{tabular}

Table 4: Correlations between level of viremia and semen parameters

\begin{tabular}{lcc}
\hline & \multicolumn{2}{c}{ PCR } \\
\cline { 2 - 3 } Semen parameters & r value & $P$ value \\
\hline Sperm count/million & $\varangle 0.459$ & $0.000^{*}$ \\
Sperm motility & $\varangle 0.250$ & $0.033^{*}$ \\
Semen volume & 0.043 & 0.715 \\
Sperm morphology & $\varangle 0.287$ & $0.014^{*}$ \\
* indicates statistical significant difference \\
r value is correlation coefficient, indicate positive correlations between \\
viremia and semen parameters
\end{tabular}

Table 5: Correlation between level of viremia and reproductive hormones

\begin{tabular}{lcc}
\hline & \multicolumn{2}{c}{ PCR } \\
\cline { 2 - 3 } Reproductive hormones & r value & P value \\
\hline SHBG & 0.002 & 0.986 \\
FSH & -0.285 & $0.015^{*}$ \\
Free testosterone & -0.250 & $0.033^{*}$ \\
PRL & 0.225 & $0.029^{*}$ \\
E2 & 0.424 & $0.000^{*}$ \\
Total testosterone & 0.123 & 0.300 \\
LH & 0.028 & 0.814 \\
* indicates statistical significant difference & \\
r value is correlation coefficient, indicates positive correlations between \\
viremia and reproductive hormones; except FSH and free testosterone \\
which have a negative correlation with viremia. \\
E2, estradiol; FSH, follicle-stimulating hormone; LH, luteinizing \\
hormone; PRL, prolactin; SHBG, sex hormone-binding globulin.
\end{tabular}

\section{DISCUSSION}

Hepatitis B infection can negatively affect male fertility in different ways. It has been reported that HBV can affect semen parameters, reproductive hormonal balance, and sperm fertilization potential ${ }^{[1]}$. In addition, transmission of infection and affection of genomic integrity are major concerns in the field of assisted reproduction ${ }^{[6]}$.

Regarding semen characteristics, we found that semen volume, sperm concentration, motility, and morphology were markedly affected in the patients' group. These findings are in agreement with those of earlier investigators ${ }^{[5,7,8]}$. However, other researchers deniedsuch finding ${ }^{[9]}$. Based on the previous reports about the deleterious effects of HBV on spermatogenesis ${ }^{[3]}$, our results make more sense.

In the present study, we found marked affection of the serum levels of T. Tes, LH, and PRL. The previous reports about the levels of hormones in HBV were controversial. In concordance with our results, it has been reported that the normal hypothalamic-pituitary-gonadal axis can be affected in liver diseases ${ }^{[10]}$.

To the best of our knowledge, this is the first study to assess the correlation between levels of viremia in male patients with chronic hepatitis B and semen parameters and reproductive hormones. 
In our study, a significant positive correlation was detected between level of viraemia and serum E2 level. It has been reported that increased serum E2 level can be associated with severe liver disease ${ }^{[1]}$.

In addition, we noted a significant positive correlation between level of viremia in male patients with chronic hepatitis B and serum PRL level. Hyperprolactinemia is known to suppress testosterone synthesis and male fertility through PRL-induced hypersecretion of adrenal corticoids by inhibiting the secretion of gonadotropinreleasing hormone through PRL receptors on hypothalamic dopaminergic neurons ${ }^{[12]}$.

In addition, we noted that there were significant negative correlations between level of viremia in male patients with chronic hepatitis B and serum levels of F. Tes and FSH.

So, our findings proved the relationship between the impaired male reproductive potential in terms of the semen characteristics and reproductive hormones, and chronic HBV infection as a possible etiological factor. In addition, we proved the direct relations between the infection's severity itself, represented by levels of viremia, and the affection of reproductive hormonal balance.

This study has some limitations. The relatively small sample size is a one. In addition, the relations between HBV and sperm function tests were not addressed.

\section{CONCLUSION}

In conclusion, our study proved the negative effects of HBV on the semen characteristics and reproductive hormonal balance. In addition and for the first time in the literature, we described the correlations with the levels of viremia. These correlations provide further support of the causal relationship between HBV and male infertility.

We recommend future researches with bigger sample sizes about the implications and correlations of HBV and all aspects of male infertility, such as sperm functions and assisted reproductive technologies.

\section{ACKNOWLEDGEMENTS}

This research was funded by Faculty of Medicine, Assiut University, Assiut, Egypt.

\section{CONFLICTS OF INTEREST}

There are no conflicts of interests.

\section{REFERENCES}

1. Oger P, Yazbeck C, Gervais A, Dorphin B, Gout C, Jacquesson L, et al. Adverse effects of hepatitis $\mathrm{B}$ virus on sperm motility and fertilization ability during IVF. Reprod Biomed Online 2011; 23:207-212.

2. Huang JM, Huang TH, Qiu HY, Fang XW, Zhuang TG, Qiu JW. Studies on the integration of hepatitis B virus DNA sequence in human sperm chromosomes. Asian J Androl 2002; 4:209-212.

3. Huang JM, Huang TH, Qiu HY, Fang XW, Zhuang TG, Liu HX, et al. Effects of hepatitis B virus infection on human sperm chromosomes. World J Gastroenterol 2003; 9:736-740.

4. Fattovich G, Bortolotti F, Donato F. Natural history of chronic hepatitisB: special emphasis on disease progression and prognostic factors. J Hepatol 2008; 48:335-352.

5. Zhou X-P, Hu X-L, Zhu Y-M, Qu F, Sun S-J, Qian $\mathrm{Y}$-L. Comparison of semen quality and outcome of assisted reproductive techniques in Chinese men with and without hepatitis. Asian J Androl 2011; 13:465469 .

6. Allahbadia GN. Viral hepatitis and Assisted reproduction. J Obstetr Gynecol India 2016; 66:397403.

7. Lorusso F, Palmisano M, Chironna M, Vacca M, Masciandaro P, Bassi E, et al. Impact of chronic viral diseases on semen parameters. Andrologia 2010; 42:121-126.

8. Chen JW, Cui Y, Zhang XX. Investigate the impact of hepatitis B virus infection on sperm DNA integrity. Chin J Exp Clin Virol 2011; 25:345-347.

9. Liu H, Geng $\mathrm{CH}$, Wang $\mathrm{W}$, Xiao KL, Xiong LK, Huang YX, et al. Effects of hepatitis B virus on human semen parameters and sperm DNA integrity. Nation J Androl 2013; 19:896-898.

10. Bannister P, Oakes J, Sheridan P, Losowsky MS. Sex hormone changes in chronic liver disease: a matched study of alcoholic versus non-alcoholic liver disease. Quart J Med 1987; 63:305-313.

11. Mao WL, Shi XP, Lou YF, Ye B, Lu YQ. The association between circulating oestradiol levels and severity of liver disease in males with hepatitis B virus infection. Liver Int 2013; 33:1211-1217.

12. Albertson BD, Sienkiewicz ML, Kimball D, Munabi AK, Cassorla F, Loriaux DL. New evidence for adirect effect of prolactin on rat adrenal steroidogenesis. Endocrine Res 1987; 13:317-333. 